\title{
REPRESENTAÇÕES SOCIAIS DE MEIO AMBIENTE: SUBSÍDIOS PARA A FORMAÇÃO CONTINUADA DE PROFESSORES
}

\author{
Social representations of the environment: \\ subsidies for the continuing education of school teachers
}

\author{
Carlos Alberto de Oliveira Magalhães Júnior ${ }^{1}$ Eduardo Augusto Tomanik ${ }^{2}$
}

Resumo: A formação de educadores ambientais deve envolver, sempre que possível, processos contínuos de estudo, atualização e a valorização dos conhecimentos dos próprios educadores. Partindo desses pressupostos, o objetivo deste trabalho foi investigar as Representações Sociais sobre o meio ambiente compartilhadas pelos professores das séries iniciais da Educação Básica da cidade de Porto Rico, Estado do Paraná, Brasil, para indicar caminhos para a formação continuada desses profissionais como Educadores Ambientais. Utilizamos a técnica de evocação de palavras para identificar os possíveis elementos que compõem as representações sociais, além de entrevistas. Identificamos que tais representações são caracterizadas por uma visão naturalista de meio ambiente e que os professores possuem conhecimentos limitados sobre o ambiente local. Esses elementos indicam a conveniência da oferta de cursos voltados para a transmissão e discussão de informações sobre o ambiente regional e para a compreensão de que os professores são, também, parte deste ambiente.

Palavras-chave: Educação ambiental. Representação do meio ambiente. Formação de professores. Formação de educador ambiental.

\begin{abstract}
The development of Environmental Educators must ideally be a continuous study process, reviewing of the state-of-the-art and with attention to the educators' experience. The goal of the present work was to investigate Social Representations about the environment, by Basic Education teachers from the City of Porto Rico, State of Paraná, Brazil, to indicate ways for the continuing education of these Educators. We used the Free Evocation of Words technique and personal interviews in order to identify the possible elements constituting the Social Representations. We identified that the representations of the analyzed group are based on a naturalist point of view of the environment. It was also verified that, concerning the local environment, the teachers' understanding is not well-founded. These findings support the need for courses devoted to the introduction and discussion of regional environment knowledge. Such studies can, subsequently, lead teachers to comprehend that they are also constituents of the environment.
\end{abstract}

Keywords: Environmental education. Representation of the environment. Teacher training. Training of environmental educator.

\footnotetext{
${ }^{1}$ Departamento de Ciências, Universidade Estadual de Maringá (UEM). Avenida Reitor Zeferino Vaz, s/n, Jardim Universitário. Goioerê, PR, Brasil.87.360-000.juniormagalhaes@hotmail.com

${ }^{2}$ Departamento de Psicologia, UEM. Maringá, PR, Brasil.
} 
Magalhães Júnior, C. A. O.; Tomanik, E. A.

\section{Introdução}

A formação de professores no Brasil é considerada insatisfatória, pois os cursos não oferecem nem a formação apropriada em conhecimentos específicos nem nos conhecimentos pedagógicos, e priorizam mais a formação teórica do que a prática (CUNHA; KRASILCHIK, 2000).

Podemos perceber, convivendo nos ambientes escolares, que a maior parte dos professores das primeiras séries do Ensino Fundamental é constituída por profissionais com formação generalista, que cursaram Magistério ou Normal, no nível médio e/ou cursos como Normal ou Pedagogia, em nível superior. Essa formação possibilita que a maioria dos professores lecione as mais variadas disciplinas que compõem as grades curriculares das séries em que vão atuar.

Meglhioratti, Bortolozzi e Caldeira (2005), Bulos e Jesus (2006) chamam a atenção para falhas na formação do conhecimento específico na formação do professor generalista para as séries iniciais da Educação Básica e indicam a ocorrência de graves problemas conceituais, por exemplo, em conteúdos da disciplina de Ciências.

Para Malacarne e Strieder (2009), no caso do ensino de Ciências, os professores dessas séries iniciais têm pouca ou nenhuma formação nas áreas das ciências que integram esta disciplina. Essa formação deficiente acarreta insegurança do docente em sua prática de ensino ao trabalhar com essa área, gerando uma dependência do livro didático, que, algumas vezes, traz conteúdos desvinculados do cotidiano e da realidade dos alunos. Gatti e Nunes (2009), e Monfredini (2009) afirmam que existem problemas em relação aos conhecimentos que os professores das séries iniciais irão ensinar, e atribuem esta deficiência às poucas disciplinas destinadas à formação específica que os docentes recebem nos cursos de Pedagogia.

Entendemos que uma das maneiras de suprir as deficiências da formação inicial seria a formação continuada. Gabini e Diniz (2009) apontam para pesquisas que reconhecem que a formação continuada é importante devido à formação inicial não conseguir atender as exigências conferidas à escola. Outro fator importante que justifica a formação contínua é referente à rápida mudança que os conceitos sofrem, além das novas produções científicas, que levam o professor a ficar com o conhecimento obsoleto (LIMA; VASCONCELOS, 2008).

Embora diversos autores reconheçam a importância de cursos de formação continuada, Schnetzler (2000) indica que muitos destes são conduzidos de maneira equivocada, pois apenas apresentam abordagens pedagógicas ou conteúdos específicos, reduzindo a função do professor à de um aplicador de receitas. Gatti (2003) mostra que cursos com estas características apresentam dificuldades em mudar as concepções e práticas pedagógicas do professor no ambiente escolar. Para esta autora, os professores são integrantes de grupos sociais que compartilham de representações as quais determinam como agem e como administram as questões que envolvem a educação e servem como filtro para os saberes que eles abordam.

Os conhecimentos adquirem sentido ou não, são aceitos ou não, incorporados ou não, em função de complexos processos não apenas cognitivos, mas, socioafetivos e culturais. Essa é uma das razões pelas quais tantos programas que visam a mudanças cognitivas, de práticas, de posturas, mostram-se ineficazes. Sua centralização apenas nos as- 
Representações sociais de meio ambiente: ...

pectos cognitivos individuais esbarra nas representações sociais e na cultura de grupos. (GATTI, 2003, p. 192)

Considerando os professores como indivíduos sociais, que compartilham, com os grupos dos quais fazem parte, conhecimentos, pensamentos e atitudes e, que estes são determinados pelas representações sociais, torna-se relevante a investigação de tais representações, para que sirvam como subsídios aos cursos de formação continuada.

\section{Representações sociais}

A todo momento, somos bombardeados por inúmeros estímulos (imagens, aromas, sons etc.) que nos geram percepções, ideias e reações. As respostas que apresentamos diante desses estímulos são mediadas pelas Representações Sociais, que são formas de conhecimento e de interpretação da realidade comuns aos integrantes de cada um dos grupos sociais dos quais fazemos parte (MOSCOVICI, 2003). É nesse sentido que Sá (1995) e Manzzotti (1997) relatam que as Representações Sociais norteiam o comportamento, as ações e a comunicação das pessoas.

A comunicação pode ser fruto das representações. Indo além desta afirmação, Duveen (2003) afirma que, sem estas, não existiria comunicação. $\mathrm{O}$ autor relata que toda criação social é estruturada e organizada por Representações.

Para Jodelet (2001), a Representação Social (RS) é um tipo de conhecimento socialmente produzido e partilhado, que difere do conhecimento científico e que proporciona a formação de uma realidade comum a um determinado grupo social.

De acordo com Moscovici (2003), a representação que apresentamos de um dado objeto não é simplesmente o nosso próprio modo de pensar, nem algo que foi imposto e transmitido unilateralmente a nós, mas um produto socialmente construído. As RS têm a função de transformar um objeto não familiar em familiar. Portanto, as representações que produzimos (de um conceito científico, de uma determinada cultura etc.) são resultado do processo de tornar algo não comum em algo conhecido e com o qual sabemos como nos relacionar.

Ferreira et al. (2007) comentam que a Teoria das Representações Sociais nos possibilita entender que diferentes grupos sociais apresentam representações distintas sobre um mesmo objeto e que isto, por sua vez, direciona a maneira como se comportam.

A formação das representações de um objeto ocorre constantemente na interação entre indivíduos sociais, num processo denominado de ancoragem e objetivação. Para Sá (1995), na ancoragem, são atribuídos significados ao objeto, vinculando a ele conceitos e valores preexistentes; assim, o desconhecido é associado a uma categoria conhecida. $\mathrm{Na}$ objetivação, o conhecimento em relação ao objeto assume forma, tornando o conceito abstrato em concreto.

Abric (2000) relata que a RS se organiza em torno de um núcleo central, que apresenta duas funções: uma geradora, que atribui significado aos outros componentes da representação, e outra organizadora, que institui ligação entre os elementos. Para Sá (1996), o núcleo pode ser formado por um ou mais elementos, e possui a característica de resistir à mudança, além de ser formado por elementos mais comuns entre as pessoas. Em volta do núcleo central, localizam-se os elementos periféricos, que são menos comuns entre os indivíduos do 
Magalhães Júnior, C. A. O.; Tomanik, E. A.

grupo e são mais sensíveis às mudanças, permitindo que novas informações sejam incluídas à representação social e podendo suportar variações advindas da prática social de cada sujeito.

Quando se objetivam mudanças nas representações de um determinado grupo, devese conhecer seu núcleo central. Resultados apontam que a mudança nas RS depende mais de ações direcionadas aos elementos nucleares (como questionamentos, confrontos etc.) do que aos periféricos (ABRIC, 2000).

Silva, Gomes e Santos (2005, p. 42) referem-se a uma representação social de natureza (RSN), destacando que essa abordagem

[...] visa compreender: os sistemas de significação socialmente construídos e compartilhados dos grupos com atuação direta na área acerca da natureza; a presença de idéias e valores que marcam o desenvolvimento do pensamento ocidental nas atuais RSN analisadas e a interface dessas representações com os comportamentos e práticas atuais na relação sociedade-natureza locais. A perspectiva é de que essas informações abram espaço para a compreensão das interações que estão se estabelecendo, entre os grupos envolvidos, para a criação e recriação do ambiente local.

Considerando as lacunas na formação inicial dos professores da Educação Básica no Brasil, sobretudo em relação aos conhecimentos científicos que regem os fenômenos presentes no ambiente, partimos da hipótese de que, analisando as representações sociais do docente sobre questões ambientais, será possível entender os possíveis caminhos de sua prática social e conhecer as concepções que possui e como age em relação a elas, o que nos indicará caminhos para o planejamento e a oferta de processos de formação continuada.

Assim, o presente trabalho teve como objetivo identificar as representações sociais que o grupo de professores da Educação Infantil e das séries iniciais do Ensino Fundamental da Educação Básica da Escola Municipal de Porto Rico, Estado do Paraná, Brasil, compartilha sobre meio ambiente, a fim de indicar caminhos para a formação continuada na área ambiental.

\section{Procedimentos}

O trabalho foi desenvolvido com 11 professoras da Escola Municipal de Porto Rico - Educação Infantil e Ensino Fundamental, única instituição de séries iniciais da Educação Básica do município (Figura 1). A seleção das professoras foi feita segundo o interesse delas em participarem da pesquisa. A realização desse trabalho ocorreu em fevereiro de 2010. 
Representações sociais de meio ambiente: ...

Figura 1. Mapa da região de Porto Rico, Paraná, Brasil

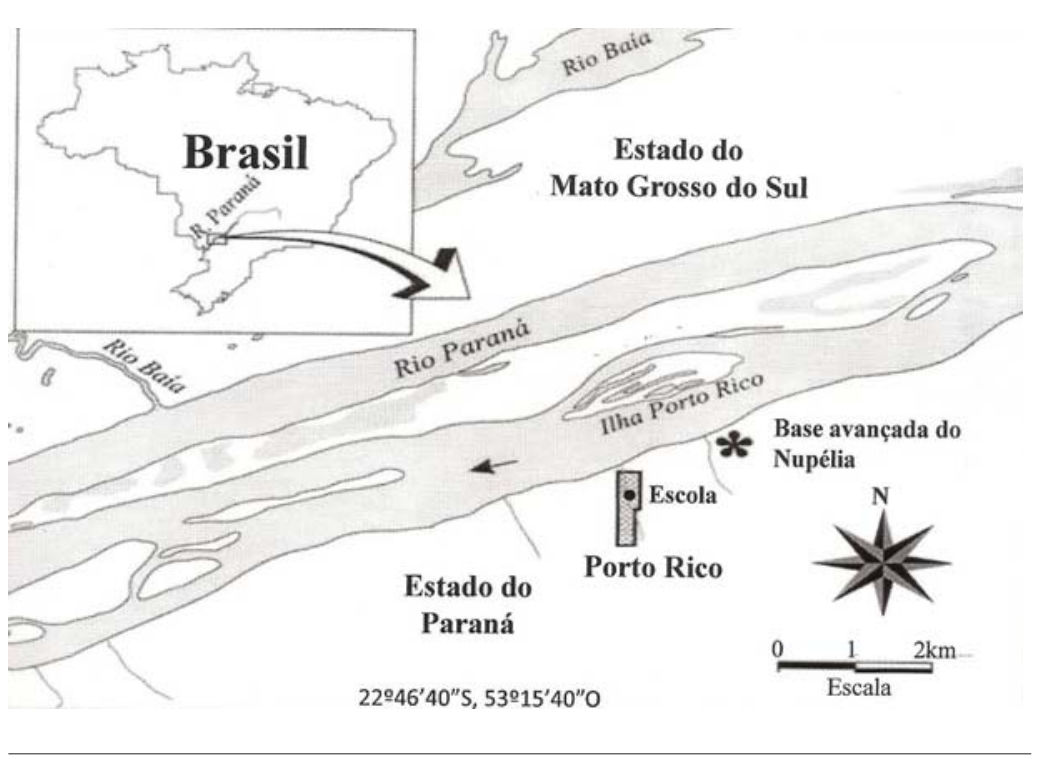

Fonte: Elaborado pelos autores.

A população desse município é de 2.531 habitantes (INSTITUTO BRASILEIRO DE GEOGRAFIA E ESTATÍSTICA, 2010). É uma cidade turística, banhada pelas águas do rio Paraná, e que atrai muitos visitantes ao longo do ano (TOMANIK; GODOY; EHLERT, 1997). Além disso, em seu território, encontra-se a Base Avançada do Núcleo de Pesquisas em Limnologia, Ictiologia e Aquicultura (Nupélia) da Universidade Estadual de Maringá (UEM), que desenvolve pesquisas em relação ao ambiente regional e que, assim, produziu inúmeras informações, que podem ser utilizadas nas escolas da região.

Para identificar as Representações Sociais dos professores em relação ao meio ambiente, adotamos a técnica de evocação livre de palavras (SÁ, 2000), que busca a identificação dos elementos nucleares e periféricos da representação, e entrevistas, que, segundo Spink (1995), proporcionam o diálogo que expressa as Representações Sociais partilhadas pelos indivíduos do grupo.

$\mathrm{Na}$ primeira técnica, os professores escreveram as cinco primeiras palavras que thes vieram à mente sobre o tema "Meio Ambiente" e, imediatamente, as classificaram segundo o grau de importância, como propõem Naiff, Naiff e Souza (2009) e Rocha (2009), atribuindo o número um para a palavra considerada mais importante, até cinco para a menos importante.

$\mathrm{Na}$ segunda técnica, fizemos entrevistas semiestruturadas, por apresentarem a vantagem de permitir ao entrevistador uma pré-sistematização das questões e, ao mesmo tempo, deixarem o entrevistado à vontade para falar (ALVES-MAZZOTTI; GEWANDSNAJDER, 1998). Os conteúdos das entrevistas foram registrados por meio de gravações de áudio e por anotações, como sugerem Lüdke e André (1986) e Spink (2002). Além de buscarmos levantar 
Magalhães Júnior, C. A. O.; Tomanik, E. A.

informações em relação às questões pessoais, como idade, sexo, tempo de experiência docente e escolaridade, também investigamos como trabalham a temática ambiental; as dificuldades de enfocarem o tema; os principais problemas ambientais da região; tipos de contribuição que oferecem para amenizar os problemas citados; questões ambientais que gostariam de conhecer melhor, e as expectativas em relação à presença da universidade na região e na escola.

As palavras evocadas foram analisadas segundo critérios apontados por Sá (1996, 2000), Naiff, Naiff e Souza (2009), Cortes Junior, Corio e Fernandez (2009) e Rocha (2009). Determinamos a Ordem Média de Evocação, utilizando a fórmula adaptada por Magalhães Júnior e Tomanik (2012), a Frequência Média das Evocações e, após organizarmos as palavras em um quadro com quatro quadrantes, pudemos identificar os possíveis elementos que compõem as representações.

Analisamos as entrevistas segundo a proposta denominada, por Bardin (1977), de análise de conteúdo, que, após uma leitura flutuante, nos possibilitou uma classificação de categorias.

Este trabalho foi aprovado pelo Comitê de Ética em Pesquisa Envolvendo Seres Humanos da Universidade Paranaense (CEPEH/UNIPAR), sob o protocolo n. 17.994/2009, e todas as professoras que participaram da pesquisa assinaram o termo de Consentimento Livre e Esclarecido.

\section{Resultados e discussão}

\section{Caracterização do grupo}

As 11 professoras que participaram da pesquisa representam 65\% do corpo docente da escola e atuam desde a Educação Infantil até o quinto ano do Ensino Fundamental.

Em relação ao perfil etário, havia uma professora com idade entre vinte e 25 anos, duas entre 25 e trinta anos, cinco entre quarenta e 45 anos, uma entre 45 e cinquenta anos e, duas entre cinquenta e 55 anos, apresentando uma média geral de quarenta anos. Em relação à experiência docente, quatro professoras apresentavam tempo de sala inferior a cinco anos, três entre dez e vinte anos, e quatro entre vinte e trinta anos, com tempo médio de 14 anos.

Todas as componentes do grupo possuíam curso superior completo. A maior parte, seis delas, é formada em Normal Superior com complementação em Pedagogia, duas em Pedagogia, duas em Normal Superior, e uma em Ciências com complementação em Química. Das 11 professoras, nove cursaram magistério de nível médio. Esses resultados estão expostos no Quadro 1.

\section{As representações expressas pelas palavras evocadas}

Ao analisarmos as evocações feitas pelas professoras, registramos 55 palavras evocadas, das quais foram descartadas nove por terem apresentado frequência igual a um, como sugerem Ferreira et al. (2005), uma vez que não apresentam importância em relação à representatividade do grupo (TEIXEIRA; BALÃO; SETTEMBRE, 2008), ficando, para a análise, 46 palavras. Em seguida, agrupamos as palavras que apresentavam mesmo sentido em grupos 
Representações sociais de meio ambiente: ...

semânticos, passando a ter 11 grupos. A média da frequência foi de 4,2 e a média das ordens médias de evocação (OME) foi de 3,0. A análise das palavras com esses valores citados resultou no Quadro 2, que mostra os quatro quadrantes com os possíveis grupos que compõem as RS.

Quadro 1. Perfil das professoras das séries iniciais da Educação Básica do município de Porto Rico, PR, Brasil

\begin{tabular}{|c|c|c|c|c|c|}
\hline \multirow[b]{2}{*}{ Professora } & \multirow[b]{2}{*}{ Idade } & \multirow[b]{2}{*}{ Tempo de Docência } & \multicolumn{2}{|c|}{ Magistério de nível médio } & \multirow[b]{2}{*}{ Formação Acadêmica } \\
\hline & & & Não & Sim & \\
\hline 1 & 40 & 15 & & $x$ & Ciências e hab. em Química \\
\hline 2 & 40 & 13 & & $x$ & Normal Superior e Pedagogia \\
\hline 3 & 41 & 23 & & $x$ & Normal Superior e Pedagogia \\
\hline 4 & 44 & 26 & & $x$ & Pedagogia \\
\hline 5 & 47 & 2 & & $x$ & Pedagogia \\
\hline 6 & 44 & 23 & & $x$ & Normal Superior \\
\hline 7 & 22 & 3 & $x$ & & Normal Superior e Pedagogia \\
\hline 8 & 53 & 30 & & $x$ & Normal Superior \\
\hline 9 & 53 & 19 & & $x$ & Normal Superior e Pedagogia \\
\hline 10 & 28 & 1 & $x$ & & Normal Superior e Pedagogia \\
\hline 11 & 26 & 3 & $x$ & & Normal Superior e Pedagogia \\
\hline
\end{tabular}

Fonte: Elaborado pelos autores.

Quadro 2. Elementos das representações sociais (RS) referentes ao meio ambiente

\begin{tabular}{|c|c|c|c|c|c|}
\hline \multicolumn{3}{|c|}{$\begin{array}{l}\text { Elementos Centrais }-1^{\circ} \text { quadrante } \\
\text { Alta } F \text { e baixa Ordem Média de Evocações } \\
\qquad f>4,2 \text { e OME }<3,0\end{array}$} & \multicolumn{3}{|c|}{$\begin{array}{l}\text { Elementos Intermediários }-2^{\circ} \text { quadrante } \\
\text { Alta F e alta Ordem Média de Evocações } \\
\qquad>4,2 \text { e OME } \geq 3,0\end{array}$} \\
\hline Grupo semântico de palavras & Freq. & OME & Grupo semântico de palavras & Freq. & OME \\
\hline Natureza & 9 & 2,2 & Animais & 5 & 4,2 \\
\hline Vida & 7 & 2,6 & & & \\
\hline Preservação & 6 & 1,8 & & & \\
\hline \multicolumn{3}{|c|}{$\begin{array}{l}\text { Elementos Intermediários }-\mathbf{3}^{\circ} \text { quadrante } \\
\text { Baixa F e baixa Ordem Média de Evocações } \\
\qquad<<4,2 \text { e } O M E<3,0\end{array}$} & \multicolumn{3}{|c|}{$\begin{array}{l}\text { Elementos Periféricos }-\mathbf{4}^{\circ} \text { quadrante } \\
\text { Baixa F e alta Ordem Média de Evocações } \\
\qquad<4,2 \text { e OME } \geq 3,0\end{array}$} \\
\hline Grupo semântico de palavras & Freq. & OME & Grupo semântico de palavras & Freq. & OME \\
\hline Água & 4 & 2,8 & Sensação de liberdade & 4 & 3,8 \\
\hline \multirow[t]{4}{*}{ Consciência } & 2 & 2,5 & Plantas & 3 & 4 \\
\hline & & & Saúde & 2 & 3,5 \\
\hline & & & Planeta & 2 & 3 \\
\hline & & & Biodiversidade & 2 & 3 \\
\hline
\end{tabular}

Fonte: Elaborado pelos autores. 
Magalhães Júnior, C. A. O.; Tomanik, E. A.

No quadrante superior esquerdo ( $1^{\circ}$ quadrante), encontram-se os elementos pertencentes ao núcleo central, que são os que apareceram com maior frequência e melhor ordem média de evocação. No quadrante inferior direito ( $4^{\circ}$ quadrante), estão os elementos periféricos, pouco evocados e com alta ordem média de evocação. Nos quadrantes intermediários $\left(2^{\circ}\right.$ e $3^{\circ}$ quadrantes) estão os elementos intermediários, que podem se aproximar dos elementos nucleares ou dos periféricos (SÁ, 1996; MARQUES; OLIVEIRA; GOMES, 2004; ROCHA, 2009).

Assim, as palavras 'Natureza', 'Vida' e 'Preservação' são os possíveis elementos que compõem o núcleo central das representações de meio ambiente desses professores. Basicamente, estas três palavras expressam uma representação de meio ambiente como sendo de "natureza", como classifica Sauvé (1997), ou de "naturalista, segundo Reigota (2010). Para a primeira autora, essa concepção tipológica de meio ambiente como natureza o considera como algo que se deve apreciar, respeitar e ser preservado. O último autor leva-nos a compreender que tais palavras evidenciam uma concepção de ambiente como natureza intocada e que não considera o homem e as relações sociais como participantes da representação.

Os elementos intermediários e periféricos também se aproximam dos sinônimos de natureza, prevalecendo os elementos naturais (como água, planta, planeta, biodiversidade) e de sentimento (sensação de liberdade). Apenas as palavras 'consciência' e 'saúde' aparecem como sendo características da categoria "globalizante", proposta por Reigota (1991), que considera uma representação de ambiente que reconhece as relações entre sociedade e natureza. Muito embora, por terem sido pouco evocadas, não representam homogeneidade no grupo, podendo ser apenas uma adaptação individual da representação, promovida por experiências particulares de alguns membros do grupo (SÁ, 1996).

Para Sauvé (1997), diante de um grupo que compartilha uma representação de ambiente calcada numa concepção de natureza, deve-se colocar seus participantes em interação com o ambiente, a fim de que possam experimentar e visualizar como ele funciona, promovendo, segundo Sato (2003, p. 13), a "renovação dos laços com a natureza, tornando-nos parte dela e desenvolvendo a sensibilidade para o pertencimento".

\section{As representações expressas pelas entrevistas}

\section{As temáticas ambientais na sala de aula}

Quando questionamos se trabalhavam com temas ambientais em suas aulas, todas as professoras indicaram que sim, mostrando que o assunto é abordado na Educação Infantil e nas primeiras séries do Ensino Fundamental, tal qual propõem os Parâmetros Curriculares Nacionais (PCNs), tema transversal Meio Ambiente (BRASIL, 1997).

Investigamos, também, quais os temas ambientais trabalhados ao longo do ano letivo. Reunimos as respostas em grupos temáticos como: 'Atributos naturais' (água, meio ambientemeio físico, plantas, animais e peixes); 'Problemas ambientais' (desperdício, poluição, poluição do rio e turismo como propulsor da poluição), e 'Cuidados com o ambiente' (como preservação e reciclagem).

Acreditamos que essas respostas também indicam as representações de ambiente dessas professoras. Complementando o resultado exposto nas evocações de palavras, pudemos perceber uma ampliação das representações, que se encaixam em diferentes categorias descritas por Sauvé (1997). 
Além da categoria "natureza", que inclui os elementos naturais, como os temas presentes no grupo 'Atributos naturais', também temos a categoria ambiente como 'problema', que caracteriza uma representação com ênfase nos impactos ambientais, que visualiza o homem como provocador de efeitos negativos ao ambiente, e algo a ser resolvido, de acordo com os temas representados pelo grupo 'Problemas Ambientais'. Em relação ao grupo 'Cuidados com o Ambiente', podemos ver uma similaridade com a categoria de representação de ambiente como 'projeto comunitário', no qual os membros do grupo analisam criticamente a natureza e possuem uma participação política na comunidade. Todos esses temas citados pelos professores abrangem tanto os elementos naturais (como a natureza os fez) como aqueles produzidos e modificados pelo homem, como é sugerido pelos PCN (BRASIL, 1997).

No entanto, apesar de notarmos novas categorias de representações nestas entrevistas, pudemos perceber que a maioria dos temas citados pelas professoras é relacionada às representações vinculadas à categoria "natureza". Bezerra e Gonçalves (2007) também mostram que, apesar de os professores apresentarem representações que se encaixam nas mais variadas categorias de representação de ambiente, a maior parte das representações está vinculada à concepção naturalista.

Buscamos investigar, também, por que as professoras trabalhavam com os temas citados. Pouco mais da metade, seis delas, indicou trabalhar com os temas devido ao fato de esses estarem previstos no programa de algumas disciplinas, como evidencia a seguinte fala: "Eu trabalho com as temáticas assim, dentro do próprio conteúdo de Ciências e Geografia" (professora 1). Complementaram dizendo que o próprio livro didático traz tais conteúdos para serem trabalhados, ou, mesmo, por terem de cumprir com um programa já preestabelecido pela escola ou por órgãos da Secretaria Estadual de Educação, como podemos notar nos relatos: "acho que é porque já vem pronto e a gente tem que seguir o conteúdo, programa da escola, já tem um roteiro ali que a gente tem que cumprir" (professora 8), ou, "vem no livro e, também, pela proposta que nós temos que trabalhar, determinada pelo núcleo de educação" (professora 11).

Parte destas professoras acaba indicando que apenas trabalham com conteúdos e conceitos oriundos de determinadas disciplinas, contrário ao sugerido pelos PCNs - temas transversais Meio Ambiente, que sugerem um trabalho transdisciplinar. Esse documento sugere que os trabalhos com o tema ambiental, no Ensino Fundamental, devem desenvolver valores, posturas éticas e atitudes, ao invés de apenas trabalharem com conceitos, pois esses serão abordados em diferentes disciplinas (BRASIL, 1997).

Além disso, esses resultados indicam que as professoras são dependentes do livro didático para trabalhar com tais temáticas. A pesquisa de Guerra, Abílio e Arruda (2005), em relação aos livros didáticos de Ciências e Geografia para o Ensino Fundamental, indicou que os temas ambientais abordados se enquadram, na maioria, na categoria definida por Sauvé (1997) como de natureza. Segundo Oliveira, Obara e Rodrigues (2007), em virtude da dependência do livro didático no trabalho com essas temáticas, têm sido geradas representações naturalistas, pois estes livros oferecem apenas informações dos aspectos físicos e biológicos do ambiente.

Assim, acreditamos que a dependência que o profissional da educação tem em relação ao livro didático tende a implicar em suas representações e, por sua vez, essas influenciam os alunos. Isso pode ser visualizado no trabalho de Tomanik e Tomanik (2002), quando indicam 
Magalhães Júnior, C. A. O.; Tomanik, E. A.

que os alunos das quintas e sextas séries do Ensino Fundamental e do Ensino Médio da cidade de Porto Rico, PR, apresentam representações de ambiente numa concepção naturalista.

As outras cinco professoras alegaram que trabalham com estes temas por acharem relevante que os alunos tenham conhecimento do meio em que vivem e para evitarem os problemas ambientais. Silva, Chaddad e Abrão (2010) relatam que a prática de ensino voltada ao ensinamento de conteúdos ambientais e sobre como conservar e preservar o meio ambiente está associada à ideia simplória de que, ao se disseminarem informações, pessoas adquirirão comportamentos e ideais para o ambiente. Apesar de entendermos que se trata do trabalho desenvolvido em séries iniciais da Educação Básica, concordamos com esses autores que tais temas devem ser tratados dentro da concepção socioambiental, que considera o ambiente natural, social, político e cultural, propondo uma reflexão e ação referentes aos aspectos sociais e naturais.

Aproveitando a reflexão das questões ambientais na prática pedagógica, questionamos como trabalhavam com esses assuntos. A maior parte das professoras relatou que o trabalho é mais expositivo, com o auxílio do livro didático e, em alguns poucos casos, com informações disponíveis na internet. Também evidenciaram que, esporadicamente, realizam saídas a campo para estudar o ambiente regional.

Silva, Jaber e Sato (2010) indicam o uso predominante do livro didático nas práticas educativas de professores em relação aos temas ambientais, e destacam que, apesar de este ser um importante recurso didático, a escola tem o desafio de buscar e produzir novas fontes de materiais com informações regionais. Concordamos com Alves et al. (2007) que essa dependência do livro didático é ligada diretamente a uma formação deficiente.

Embora muitas dessas professoras tenham manifestado a dependência do livro didático, algumas evidenciaram a preocupação de usar exemplos de temas que pertencem ao cotidiano dos alunos, conforme destacado nas frases: "trabalho com as cheias do rio, devido alguns alunos que a gente tem, que são moradores de ilhas" (professora 4) ou "a gente tem feito visitas na barranca do rio para ver peixes, a gente trabalha com o que o aluno sabe sobre nome de peixes" (professora 8).

Apesar da preocupação de algumas com a contextualização do assunto, a maior parte fica limitada ao conteúdo do livro; e concordamos com Oliveira, Obara e Rodrigues (2007) quando relatam que o trabalho com temas ambientais baseado num ensino livresco acarreta uma negação do ambiente local.

Finalizando as investigações sobre a abordagem dos temas em sala de aula, perguntamos quais eram as dificuldades que elas encontravam para trabalhar com os temas relacionados a meio ambiente nas aulas. A maioria citou que as dificuldades são em relação à falta de recursos (ônibus para deslocamentos, dinheiro para uma saída de barco, falta de materiais didáticos, entre outros) e conseguir sair da teoria para atividades práticas, como aula de campo, uma vez que reconhecem que possuem limitações no conhecimento das temáticas e, algumas vezes, os alunos sabem mais sobre determinado componente do ambiente do que elas. Parte disso aparece nos relatos: "sinto dificuldade de não poder ir lá mostrar pro aluno a realidade, ficar no abstrato e não lidar com o concreto" (professora 3) e, "eles passam coisas do nosso rio que eu mesma não conheço, mas eles sabem" (professora 2).

Silva (2008) indica que a falta de recursos pedagógicos e financeiros para os estabelecimentos de ensino desenvolverem trabalhos na área ambiental é um fator limitante, além de 
Representações sociais de meio ambiente: ...

professores mal preparados. Percebemos que a formação deficiente que tiveram nas áreas das ciências da natureza, como indicam Malacarne e Strieder (2009), acaba promovendo dificuldades de trabalho com aulas que fogem do modelo tradicional de ensino, como em aulas de campo.

De certa forma, acreditamos que a falta de conhecimento de elementos e fenômenos naturais inibe o trabalho de campo destas profissionais, uma vez que este tipo de modalidade didática requer do professor um conhecimento amplo do ambiente a ser trabalhado e, que de forma contrária, o trabalho em sala e com o auxílio do livro didático proporciona uma maior segurança na atividade de ensino.

A Figura 2 expõe parte dos resultados apresentados até o momento.

Figura 2. Diagrama das representações de ambiente de professoras de Porto Rico, PR

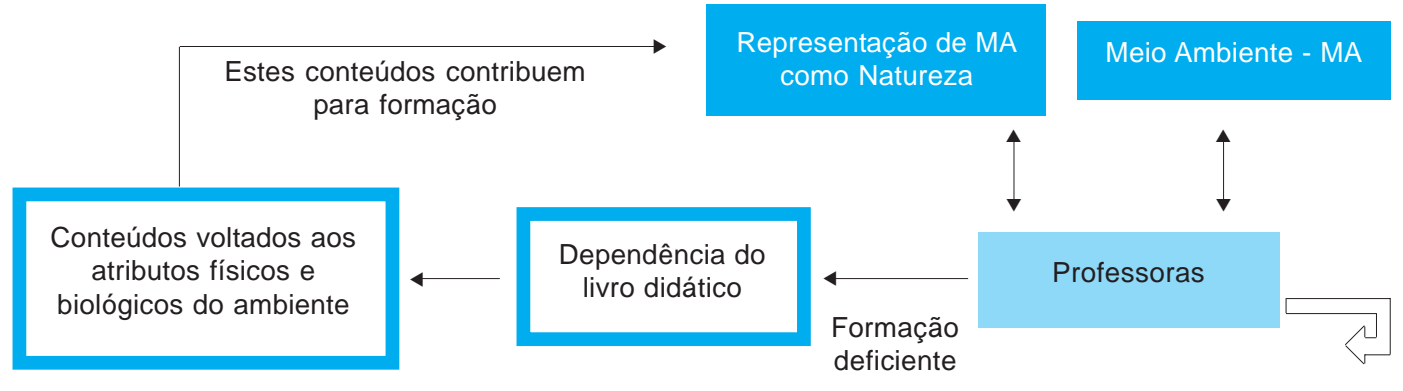

Fonte: Elaborado pelos autores.

\section{Os problemas ambientais na região}

Quando questionamos sobre os problemas ambientais da região, vimos esse grupo direcionar uma variedade de problemas mais relacionados ao rio. Em primeiro lugar, indicam a poluição do rio provocada pelo lixo despejado pelos turistas, seguida pela poluição do rio provocada pelo esgoto que é nele descartado e o desmatamento, sobretudo o relacionado à mata ciliar; graças ao qual alegam que as margens do rio ficam desprotegidas. Menos frequentes, apareceram indicações de problemas com o lixo na cidade e a caça de animais.

Embora não diretamente aparecendo como resposta à pergunta, alguns membros deste grupo indicaram o turismo como um problema para os moradores da região, pois, em suas representações, além de contribuírem para a produção de resíduos sólidos, provocam impacto na paisagem local, mudando a cultura arquitetônica das novas construções, além de provocarem uma supervalorização dos imóveis e, por sua vez, impossibilitando muitos munícipes de adquirem a casa própria. Parte desses impactos sociais, também, é indicada por Violante e Silva (2008) num estudo realizado nesta região.

A maioria destes problemas ambientais indicados pelas professoras diz respeito aos impactos nos sistemas naturais, indicando, mais uma vez, as representações sociais numa 
Magalhães Júnior, C. A. O.; Tomanik, E. A.

visão naturalista, em conformidade com os dados publicados por Obara, Pereira e Navasconi (2003), com um grupo de professores do colégio estadual que funciona no mesmo espaço em que as professoras desta pesquisa trabalham.

Acreditamos que a maior parte das representações sobre os problemas ambientais da região está relacionada ao rio, devido à maioria das atividades econômicas da região estar, mesmo que indiretamente, relacionada a este elemento da natureza, justificando a imagem do rio ocupar uma parte importante nas representações de problemas ambientais dessas professoras (TOMANIK, 1997).

Além das representações de problemas ambientais serem mais centradas nos elementos naturais do que nos socioambientais, elas compreendem o problema ambiental apenas como decorrência da ação humana, não abrangendo as ações naturais, como também apontam Marques et al. (2007) em seu trabalho com professores.

Aproveitando a temática, questionamos as professoras em relação à contribuição à redução dos problemas ambientais. O ponto mais fortemente evidenciado pelas professoras para amenizar ou solucionar os problemas ambientais citados foi o trabalho de orientação com os alunos, conforme nota-se nas frases: "conscientizando os alunos, trabalhando com eles" (professora 10) e, "como professora, faço o trabalho com os alunos" (professora 6). Poucas delas mencionaram a orientação a outras pessoas da sociedade, ou mencionaram a contribuição pessoal em relação a algumas questões ambientais, como exposto no trecho a seguir: "estou começando a fazer relacionada a mim mesmo, já na minha ação dentro de casa, recolhendo o lixo, levando na rua, não deixando nada que pode acumular água, que tem o problema da dengue, e às vezes cobrando, como citei o caso da rede de esgoto, cobrando do lado político" (professora 1).

Manzzotti (1997) relata que o discurso de alguns documentos oficiais acaba influenciando nas representações dos professores. Assim, acreditamos que essa maior atribuição da ação docente na resolução aos problemas ambientais e/ou a necessidade de se trabalhar com os alunos essas questões, são decorrentes das informações difundidas em documentos oficiais que acabam fazendo parte das representações desse grupo, que, como mostramos, assumem tal responsabilidade. Em contrapartida, pouco é assumida a responsabilidade social em outras situações do cotidiano fora da escola, evidenciando o afastamento do homem como parte da natureza e descomprometido com seu desenvolvimento sustentável, como relatam Sauvé (1997) e Reigota (2010) quando descrevem a categoria de meio ambiente como natureza/naturalista.

\section{Temas ambientais de interesse de aprendizagem}

Quando questionadas sobre quais temas teriam interesse para estudar, indicaram quatro assuntos: Peixes, Poluição, Rio/Água e Outros Animais, apresentados aqui em ordem decrescente de citações. Mais uma vez, pudemos identificar, nas respostas, o reconhecimento da deficiência do conhecimento de alguns temas do ambiente local, como indicado nestes trechos: "como educadora eu não conheço todas as espécies de peixes que tem aqui e, às vezes, trabalhando lá pedagogicamente os alunos conhecem mais que a própria professora" (professora 1) e "eu particularmente não entendo nada de peixe" (professora 7), justificando ser um tema importante como formação complementar para a prática docente. 
Além do autodiagnóstico da falta de conhecimento de alguns elementos do ambiente regional, Obara, Pereira e Navasconi (2003) indicam que os professores trabalham com temas muito gerais e que não valorizam as características locais, uma vez que são oriundos dos livros didáticos. Também possuem necessidade de aprofundamento de informações sobre a região, sendo necessários cursos de formação engajados nos temas do ambiente regional.

Neste ponto, acreditamos que parte do conhecimento produzido pelas pesquisas desenvolvidas pela UEM na região contribuirá para a formação destes profissionais, melhorando a qualidade de ensino.

Muitos resultados de estudos poderão contribuir para o conhecimento amplo dos elementos ambientais da região, sobretudo aqueles nos quais as professoras demonstraram interesse; e, também, para a melhor compreensão dos problemas ambientais locais, como: o desmatamento, a pecuária, a mineração, a monocultura, as queimadas, a pesca predatória, as barragens construídas no rio Paraná, o turismo, entre outros fatores, como indicam Godoy e Ehlert (1997), Agostinho, Thomaz e Nakatani (2000), Ortêncio Filho e Reis (2009) e Rocha (2010).

\section{Expectativas na região em relação à universidade}

Questionamos os professores se eles sabiam das pesquisas que a Universidade Estadual de Maringá (UEM) desenvolve na região, quais eram as expectativas que tinham quando viam estas pesquisas sendo desenvolvidas, e se já haviam tido algum retorno de alguma delas para o processo educacional.

Todo o grupo indicou saber que a UEM tinha uma base de pesquisa na região, porém, muitas das professoras não sabiam quais os tipos de trabalhos eram desenvolvidos e, por isso, não tinham expectativas em relação a elas. Outra parte, mesmo não sabendo especificamente sobre os temas pesquisados, tinha a perspectiva de que tais trabalhos poderiam melhorar a região, por exemplo, contribuindo para amenizar os problemas ambientais.

Algumas professoras relataram ter a expectativa da contribuição dessas pesquisas no cotidiano escolar, como nas frases: "espero que possa acrescentar mais no meu conhecimento e que estou sentindo falta para que eu possa estar aplicando na sala de aula, na minha prática" (professora 5), e "a minha expectativa é que venham mais numa linguagem pedagógica. Que às vezes você pega um texto lá e não tem nada a ver, minha expectativa é que traz uma linguagem melhor, mais fácil, para criança” (professora 2).

Em relação ao retorno destas pesquisas para a escola, cinco das professoras disseram que uma pesquisadora já havia trabalhado algum tema sobre o ambiente local, mas que isto somente havia ocorrido uma vez. As outras seis, coincidentemente, as mais novas de tempo de carreira, nunca tiveram nada de retorno. Tal trabalho mencionado foi decorrente do desenvolvimento da tese de doutorado de Periotto (2008), que, entre outras atividades, desenvolveu um curso sobre peixes.

Obara, Pereira e Navasconi (2003) relatam que muitas pesquisas foram feitas pela UEM na região, e que seus resultados são importantes para a formação dos professores. Guerriero (2008) comenta que é importante que as pesquisas deem um retorno de seus resultados à comunidade, tanto por um dever ético como social. Assim, acreditamos que parte dessas pesquisas sirva para enriquecer o conhecimento dos professores de Porto Rico. 
Magalhães Júnior, C. A. O.; Tomanik, E. A.

\section{Considerações finais}

A formação de professores para a Educação Infantil e para as séries iniciais do Ensino Fundamental é limitada em relação aos conhecimentos científicos que compreendem o ambiente e, assim, tornam-se necessárias outras maneiras de se prepararem tais profissionais, como, por exemplo, por meio de cursos de formação continuada.

Compreendemos que as Representações Sociais sobre meio ambiente influenciam a prática pedagógica dos professores. Por sua vez, entendemos que investigá-las possibilita-nos tanto compreender estas práticas quanto indicar caminhos para a formação continuada dos docentes em exercício.

Os resultados desta pesquisa indicaram que os elementos nucleares das representações destes profissionais estão vinculados, mais fortemente, à visão naturalista de meio ambiente e que, provavelmente, estão vinculadas e influenciadas, em parte, pelo livro didático.

A dependência do livro didático nos indica duas situações: primeiro, que reflete a formação deficiente dessas profissionais ao trabalharem com a temática ambiental, e que a abordagem dos conteúdos pouco privilegia as características socioambientais da região.

Os resultados de anos de pesquisas que a Universidade Estadual de Maringá vem desenvolvendo na região de Porto Rico podem contribuir muito com os conhecimentos dessas professoras em relação ao ambiente local. Além de entendermos que esses resultados podem ser utilizados para a formação das docentes em atuação, elas demonstram interesse em conhecer e usufruir deles para enriquecimento de suas aulas.

Por fim, essas representações expostas pelas professoras sugerem uma formação continuada em temas diversos em relação ao ambiente regional, tanto no objetivo de construir o conhecimento específico de seus elementos quanto em táticas de imersão das professoras na natureza, para compreensão de que fazem parte do ambiente e são corresponsáveis por ele.

Assim, a hipótese de que analisar as representações sociais dos docentes sobre temas

ambientais para entender os caminhos de sua prática social e conhecer as concepções que estes possuem e como agem em relação a elas nos indicaria caminhos para o planejamento e a oferta de processos de formação continuada foi corroborada por esta pesquisa.

\section{Referências}


Representações sociais de meio ambiente: ...

ABRIC, J. C. A Abordagem estrutural das representações sociais. In: MOREIRA, A. S. P.; OLIVEIRA, D. C. (Org.). Estudos interdisciplinares de representação social. 2. ed. Goiânia: AB, 2000. p. 27-38.

AgOSTINHO, A. A.; THOMAZ, S. M.; NAKATANI, K. A planície alagável do rio Paraná: estrutura e processo ambiental - relatório 2000. Disponível em: <http:// www.peld.uem.br/Relat2000/index.htm >. Acesso em: 12 jun. 2008.

ALVES, P. M. A. et al. Perfil do professor de ciências das séries iniciais do ensino fundamental da rede municipal de Jataí-GO. In: SIMPÓSIO NACIONAL DE ENSINO DE FÍSICA, 17., 2007, São Luiz. Anais... São Luiz: SBF, 2007. p. 1-10.

ALVES-MAZZOTTI, A. J.; GEWANDSZNAJDER, F. O método nas ciências naturais e sociais: pesquisa quantitativa e qualitativa. 2. ed. São Paulo: Pioneira, 1998.

BARDIN, L. Análise de conteúdo. Lisboa: Edições 70, 1977.

BEZERRA, T. M. O.; GONÇALVES, A. A. C. Concepções de meio ambiente e educação ambiental por professores da Escola Agrotécnica Federal de Vitória de Santo Antão-PE.

Biotemas, Florianópolis, v. 20, n. 3, p. 115-125, set. 2007.

BRASIL. Ministério da Educação. Parâmetros curriculares nacionais: meio ambiente e saúde. Brasília, MEC, 1997. v. 9

BULOS, A. M. M.; JESUS, W. P. Professores generalistas e a matemática nas séries iniciais. In: ENCONTRO BRASILEIRO DE ESTUDANTES DE PÓS-GRADUAÇÃO EM EDUCAÇÃO MATEMÁTICA, 10., 2006, Belo Horizonte. Anais... Belo Horizonte: UFMG, 2006. p. 1-12.

CORTES JUNIOR, L. P.; CORIO, L.; FERNANDEZ, C. As representações sociais de química ambiental dos alunos iniciantes na graduação em química. Química Nova na Escola, São Paulo, n. 1, v. 31, p. 46-54, fev. 2009.

CUNHA, A. M. O.; KRASILCHIK, M. A formação continuada de professores de ciências: percepções a partir de uma experiência. In: REUNIÃO DA ASSOCIAÇÃO NACIONAL DE PÓS-GRADUAÇÃO E PESQUISA EM EDUCAÇÃO, 23., 2000, Caxambú. Anais... Caxambú: ANPED, 2000. p. 1-14.

DUVEEN, G. Introdução: o poder das idéias. In: MOSCOVICI, S. Representações sociais: investigações em psicologia social. 3. ed. Petrópolis: Vozes, 2003. p. 7-28.

FERREIRA, V. C. P. et al. A representação social do trabalho: uma contribuição para o estudo da motivação. Estação Científica, Juiz de Fora, v. 1, p. 1-13, 2005.

FERREIRA, C. F. B. et al. Análise das representações sociais sobre meio ambiente de técnicos e professores das Secretarias de Educação e Meio Ambiente de municípios da Bacia de Campos - RJ. In: ENCONTRO NACIONAL DE PESQUISA EM EDUCAÇÃO EM CIÊNCIAS, 6., 2007, Florianópolis. Atas... Florianópolis: ENPEC, 2007. 
Magalhães Júnior, C. A. O.; Tomanik, E. A.

GABINI, W. S.; DINIZ, R. E. S. Os professores de química e o uso do computador em sala de aula: discussão de um processo de formação continuada. Ciência \& Educação, Bauru, v. 15 , n. 2 , p. $343-58,2009$.

GATTI, B. A. Formação continuada de professores: a questão psicossocial. Cadernos de Pesquisa, São Paulo, n. 119, p. 191-204, jul. 2003.

GATTI, B. A.; NUNES, M. M. R. (Org.). Formação de professores para o ensino fundamental: estudo de currículos das licenciaturas em pedagogia, língua portuguesa, matemática e ciências biológicas. São Paulo: FCC/DPE, 2009. v. 29.

GODOY, A. M. G.; EHLERT, L. G. Porto Rico: a difícil sobrevivência do homem e do meio ambiente. In: VAZZOLER, A. E. A. M.; AGOSTINHO, A. A.; HAHN, N. S. (Ed.). A planície de inundação do Alto Rio Paraná: aspectos limnológicos e sócio-econômicos. Maringá: Eduem, 1997. p. 437-453.

GUERRA, R. A. T.; ABÍLIO, F. J. P.; ARRUDA, F. N. F. Meio ambiente e educação ambiental: formação continuada de professores de ensino fundamental do município de Pitimbú - PB. In: CONGRESSO INTERNACIONAL DE FORMAÇÃO CONTINUADA E PROFISSIONALIZAÇÃO DOCENTE, 2005, Natal. Anais... Natal: Editora UFPB, 2005. v. 1. p. 513-514.

GUERRIERO, I. C. Z. Síntese das reflexões da reunião sobre ética em pesquisa qualitativa em Saúde, Guarujá, SP. Ciência e Saúde Coletiva, Rio de Janeiro, v. 13, n. 2, p. 459-463, 2008.

INSTITUTO BRASILEIRO DE GEOGRAFIA E ESTATÍSTICA. XII censo

demográfico. [S.1.]: IBGE, 2010. Disponível em: <http://www.censo2010.ibge.gov.br/>. Acesso em: 12 jan. 2011.

JODELET, D. Representações sociais: um domínio em expansão. In.: representações sociais. Rio de Janeiro: EdUerj, 2001. p. 17-44. (Org.). As

LIMA, K. E. C.; VASCONCELOS, S. D. O professor de ciências das escolas municipais de recife e suas perspectivas de educação permanente. Ciência \& Educação, Bauru, v. 14, n. 2, p. 347-364, 2008.

LÜDKE, M.; ANDRÉ, M. E. D. A. Pesquisa em educação: abordagens qualitativas. São Paulo: EPU, 1986.

MAGALHÃES JÚNIOR, C. A. O.; TOMANIK, E. A. Representações sociais e direcionamento para a educação ambiental na Reserva Biológica das Perobas, Paraná. Investigações em Ensino de Ciências, Porto Alegre, v. 17, n. 1, p. 227-248, 2012.

MALACARNE, V.; STRIEDER, D. M. O desvelar da ciência nos anos iniciais do ensino fundamental: um olhar pelo viés da experimentação. Vivências, Erechim, v. 5, n. 7, p.75-85, 2009. 
Representações sociais de meio ambiente: ...

MANZZOTTI, T. B. Representação social de "problema ambiental": uma contribuição à educação ambiental. Revista Brasileira de Estudos Pedagógicos, Brasília, v. 78, n. 188/ 189/190, p.186-123, jan./dez. 1997.

MARQUES, S. C.; OLIVEIRA, D. C.; GOMES, A. M. T. AIDS e representações sociais: uma análise comparativa entre subgrupos de trabalhadores. Psicologia: Teoria e Prática, São Paulo, v. 6, n. 3, p. 91-104, 2004.

MARQUES, C. A. et al. Visões de meio ambiente e suas implicações pedagógicas no ensino de química na escola média. Química Nova, São Paulo, v. 30, n. 8, p. 2043-2052, 2007.

MEGLHIORATTI, F. A.; BORTOLOZZI, J.; CALDEIRA, A. M. A. Educação, conteúdo disciplinar e atitude crítica na formação de professores. Revista Científica Eletrônica de Pedagogia, Garça, n. 5, jan. 2005.

MONFREDINI, I. Trabalho, profissão docente e o problema do conhecimento na formação inicial de professores. Eccos: Revista Científica, São Paulo, v. 11, n. 2, p. 605-620, jul./dez. 2009.

MOSCOVICI, S. Representações sociais: investigações em psicologia social. 3. ed. Petrópolis: Vozes, 2003.

NAIFF, D. G. M.; NAIFF, L. A. M.; SOUZA, M. A. As representações sociais de estudantes universitários a respeito das cotas para negros e pardos nas universidades públicas

brasileiras. Estudos e Pesquisas em Psicologia, Rio de Janeiro, v. 9, n. 1, p. 216-229, 2009.

OBARA, A. T.; PEREIRA, S.; NAVASCONI, C. L. R. D. Educação ambiental no ensino formal: a experiência do colégio Manoel Romão Netto (Porto Rico - PR). In: SIMPÓSIO SUL BRASILEIRO DE EDUCAÇÃO AMBIENTAL, 2., 2003, Itajaí. Anais... Itajaí: Univali, 2003. 01 CD-ROM.

OLIVEIRA, A. L.; OBARA, A. T.; RODRIGUES, M. A. Educação ambiental: concepções e práticas de professores de ciências do ensino fundamental. Revista Electrónica de Enseñanza de las Ciencias, Vigo, v. 6, n. 3, p. 471-495, 2007.

ORTÊNCIO FILHO, H.; REIS, N. R. Species richness and abundance of bats in fragments of the stational semidecidual forest, Upper Paraná River, southern Brazil. Brazilian Journal of Biology Supplement, São Carlos, v. 69, n. 2, p. 727-734, 2009.

PERIOTTO, T. R. C. Estudo e práticas colaborativas não presenciais em educação ambiental: implantação de um solução na web para a interação com as escolas da região de inundação do alto rio Paraná. 2008. 360f. Tese (Doutorado) - Departamento de Biologia, Universidade Estadual de Maringá, Maringá, 2008.

REIGOTA, M. O meio ambiente e suas representações no ensino em São Paulo, Brasil. Uniambiente, Brasília, v. 2, n. 1, p. 27-30, 1991.

Meio ambiente e representação social. 8. ed. São Paulo: Cortez, 2010. 
Magalhães Júnior, C. A. O.; Tomanik, E. A.

ROCHA, A. G. Representações sociais sobre novas tecnologias da informação e da comunicação: novos alunos, outros olhares. 2009. 314 f. Dissertação (Mestrado em Educação) - Universidade Católica de Santos, Santos, 2009.

ROCHA, P. S. Indicadores de alteração hidrológica no Alto Rio Paraná: intervenções humanas e implicações na dinâmica do ambiente fluvial. Sociedade $\boldsymbol{\&}$ Natureza, Uberlândia, v. 22, n. 1, p. 191-211, abr. 2010.

SÁ, C. P. Representações sociais: o conceito e o estado atual da teoria. In.: SPINK, M. D. (Org.). O conhecimento no cotidiano: as representações sociais na perspectiva da psicologia social. São Paulo: Brasiliense, 1995. p. 19-45.

. Núcleo das representações sociais. Petrópolis: Vozes, 1996.

A Representação social da economia brasileira antes e depois do Plano Real. In:

MOREIRA, A. S. P.; OLIVEIRA, D. C. (Org.). Estudos interdisciplinares de representação social. 2. ed. Goiânia: AB, 2000. p. 49-69.

SATO, M. Educação ambiental. São Carlos: Rima, 2003.

SAUVÉ, L. Educação ambiental e desenvolvimento sustentável: uma análise complexa. Revista de Educação Pública, Cuiabá, n. 10, v. 6, p. 72-103, 1997.

SCHNETZLER, R. P. O professor de ciências: problemas e tendências de sua formação. In: PACHECO, R. P.; ARAGÃO, R. M. R. (Org.). Ensino de ciências: fundamentos e abordagens. Campinas: UNIMEP, 2000. p. 12-41.

SILVA, A. C. S. O trabalho com educação ambiental em escolas de ensino fundamental. Remea: Revista Eletrônica do Mestrado em Educação Ambiental, Rio Grande, v. 20, p. 37-52, jan.-jun. 2008.

SILVA, R. H. A.; CHADDAD, F. R.; ABRÃO, L. A. Concepções de educação ambiental em alunos de um curso de ciências biológicas. Educação Ambiental em Ação, Novo Hamburgo, v. 9, n. 32, 2010.

SILVA, L. M. A.; GOMES, E. T. A.; SANTOS, M. F. S. Diferentes olhares sobre a natureza: representação social como instrumento para educação ambiental. Estudos de Psicologia, Natal, v. 10, n. 1, p.41-51, 2005.

SILVA, R.; JABER, M.; SATO, M. Tecendo a educação ambiental com fios amazônicos. Revista de Educação Pública, Cuiabá, v. 19, n. 39, p. 115-130, 2010.

SPINK, M. D. O estudo empírico das representações sociais. In: SPINK, M. D. (Org.). O conhecimento no cotidiano: as representações sociais na perspectiva da psicologia social. São Paulo: Brasiliense, 1995. p. 85-108.

SPINK, M. J. Desvendando as teorias implícitas: uma metodologia de análise das representações sociais. In: GUARESCHI, P.; JOVCHELOVITCH, S. (Org.). Textos em representações sociais. 7. ed. Petrópolis: Vozes, 2002. p. 117-145. 
Representações sociais de meio ambiente: ...

TEIXEIRA, M. C. T. V.; BALÃO, S. M. S.; SETTEMBRE, F. M. Saliência de conteúdos de representação social sobre o envelhecimento: análise comparativa entre duas técnicas associativas. Revista Enfermagem UERJ, Rio de Janeiro, v. 16, n. 4, p. 518-524, out./dez. 2008.

TOMANIK, E. A. Elementos sobre as representações sociais dos pescadores "profissionais" de Porto Rico. In: VAZZOLER, A. E. A. M.; AGOSTINHO, A. A.; HAHN, N. S. (Ed.). A planície de inundação do Alto Rio Paraná: aspectos limnológicos e sócio-econômicos. Maringá: Eduem, 1997. p.437-453.

TOMANIK, E. A.; GODOY, A. G.; EHLERT, L. G. A vida na região: dados socioeconômicos do núcleo urbano de Porto Rico. In: VAZZOLER, A. E. A. M.; AgOSTINHO, A. A.; HAHN, N. S. A planície de inundação do alto rio Paraná: aspectos físicos, biológicos e sócio-econômicos. Maringá: Eduem, 1997. p. 395-413.

TOMANIK, E. A.; TOMANIK, M. C. O ambiente conhecido: estudo das representações sociais sobre a natureza compartilhadas pelos adolescentes de Porto Rico, Paraná. In: A planície de inundação do alto rio Paraná. Maringá: Nupélia, 2002. Disponível em: <http://www.peld.uem.br/Relat2000/apresent2000.htm>. Acesso em: 12 jun. 2008.

VIOLANTE, A. C.; SILVA, A. J. Questões turísticas em Porto Rico-Paraná. In: ENCONTRO NACIONAL DE ENGENHARIA DE PRODUÇÃO, 28., 2008, Rio de Janeiro. Atas... Rio de Janeiro: Abepro, 2008. p. 1-12. 